YOUNG PEOPLE

\title{
Biological and hormonal markers of chlamydia, human papillomavirus, and bacterial vaginosis among adolescents attending genitourinary medicine clinics
}

\author{
L Brabin, E Fairbrother, D Mandal, S A Roberts, S P Higgins, S Chandiok, P Wood, G Barnard, \\ H C Kitchener
}

Sex Transm Infect 2005;81:128-132. doi: 10.1136/sti.2004.010223

See end of article for authors' affiliations

Correspondence to: Dr L Brabin, Academic Unit of Obstetrics and Gynaecology and Reproductive Health Care, Research Floor, St Mary's Hospital, Whitworth Park, Manchester M13 OJH, UK; loretta.brabin@ manchester.ac.uk

Accepted for publication 18 May 2004
Objective: To assess maturity indices, menstrual patterns, hormonal factors, and risk of adolescent genital tract infections.

Methods: Cross sectional study in three genitourinary medicine clinics. Females 17 years or less, within 5 years of menarche, or reporting oligo-amenorrhoea were screened for genital tract infections and menstrual cycle characteristics determined. The outcome measures were risk factors associated with chlamydia, human papillomavirus (HPV DNA) and bacterial vaginosis (BV), separately and pooled. Correlations between estrone-3-glucuronide (E3G) and pregnanediol-3 $\alpha$-glucuronide (P3G) hormone concentrations and chlamydia, HPV, and BV.

Results: Among 127 adolescents, HPV was present in $64.4 \%$ (95\% Cl: 54.5 to 74.3 ), BV in $33.9 \%$ (19.1 to $34.5)$, and chlamydia in $26.8 \%$ (19.1 to 34.5). Breast maturity, oligomenorrhoea, and older gynaecological age were associated with lower risk of all infections. After adjustment for calendar age, race, and behavioural factors, gynaecological age remained significant $(O R=0.7,0.6-0.9 ; p=0.008)$. Behavioural risk factors differed by infection. Smoking was protective for HPV $(O R=0.1,0.0$ to 0.9 ; $p=0.007)$, and a recent new partner for chlamydia $(O R=0.3,0.1$ to $0.9 ; p=0.024)$. Sex during menses was associated with increased $B V$ risk $(O R=3.3,1.5$ to $7.2 ; p=0.003)$. Chlamydia was higher among adolescents who used emergency contraception $(2.5 ; 1.1$ to $5.9, p=0.029)$ and lower among those using condoms at last sex $(O R=0.3,0.1$ to $0.9 ; p=0.015)$. Among 25 adolescents not using hormonal contraceptives, 15 had disturbed or anovulatory cycles. Chlamydia risk was inversely associated with P3G concentrations (Mann-Whitney; $p=0.05$ ).

Conclusions: Adolescents engaging in high risk behaviour at a young gynaecological age are susceptible to multiple infections. Adolescent clinical assessment should include gynaecological age. tion $\mathrm{n}$ the United Kingdom, rates of sexually transmitted infections are very high in female adolescents. ${ }^{1}$ Age at first intercourse has declined, adolescents do not always use condoms effectively and consistently, and the number of lifetime and concurrent partnerships has increased. ${ }^{2}$ Sexual behaviour does not entirely explain the high infection rates, and biological and hormonal factors are almost certainly implicated. ${ }^{3}$ Adolescents develop at different rates, and those exposed to genital infections before maturation is complete could be more susceptible to infection. Menarche, the most common maturity marker, follows the pre-pubertal growth spurt, may occur early or late in adolescence, and is not the culmination of maturation. Following menarche, menstrual cycle disturbances, ${ }^{4}$ persisting ectopy, penetrable cervical mucus, ${ }^{6}$ low IgA levels ${ }^{6}$ and hormonal contraception $^{78}$ could each increase susceptibility to, or ability to clear, genital infections.

Our aim was to assess whether adolescent maturity indices, menstrual patterns, and hormonal factors were associated with higher frequency of genital infections.

\section{METHODS}

Recruitment

Study population

We invited adolescents attending three genitourinary medicine (GUM) clinics in Manchester to participate.

Participants

Adolescents were recruited if they complained of oligoamenorrhoea, were within 5 years of menarche, or their calendar age was 17 years or less. They were excluded if premenarcheal, pregnant or breast feeding in the last 3 months, treated for a genital infection in the past 4 weeks, or had started, or stopped, using hormonal contraception within the last month. All gave informed written consent, and if younger than 16 years, were assessed for Gillick competency (that is, sufficient intelligence and understanding to be treated without parental consent). Three local NHS ethical research committees approved the study. A questionnaire (pre-piloted) established contraceptive, menstrual, sexual and pregnancy histories, and socioeconomic status. Pictorial charts were used for self grading breast and pubic hair stages. ${ }^{9}$ Body mass index (weight $(\mathrm{kg})$ per height $(\mathrm{m})^{2}$ ) was calculated. As part of a standardised history and examination procedure, area of ectopy was drawn on a schematic diagram.

Collection of samples

Endocervical swabs for culture of Neisseria gonorrhoeae, and combined endocervical swabs and urine samples for Chlamydia trachomatis ${ }^{10}$ were taken. For HPV DNA detection a spatula was rotated through $360^{\circ}$ within the transformation zone of the cervix and placed in saline. Swabs from the cervix and vulva were placed in viral medium for herpes simplex virus types 1 and 2 (HSV-1/HSV-2) detection. Wet mounts were prepared from a high vaginal swab to examine for

Abbreviations: BV, bacterial vaginosis; E3G, estrone-3-glucuronide; GUM, genitourinary medicine; HPV, human papillomavirus; P3G, pregnanediol-3 $\alpha$-glucuronide; PCR, polymerase chain reaction 
Ttichomonas vaginalis and Candida albicans. Vaginal $\mathrm{pH}$ was measured and a Gram stain for bacterial vaginosis (BV) was prepared. A blood sample was collected for detection of antibodies to $T$ pallidum and anonymous HSV-1/HSV-2 screening. Adolescents not using hormonal contraception were offered, and shown how to use, a fertility monitor (ClearPlan Easy, Unipath) over one menstrual cycle, in order to characterise their cycles and the predicted peri-ovulatory luteinising hormone surge. ${ }^{11}$ Self collected urine samples were obtained on alternate days between days 12 and 26 of the menstrual cycle. These samples were stored frozen $\left(-80^{\circ}\right)$ at the University of Southampton Endocrine Unit for determination of estrone-3-glucuronide (E3G) and pregnanediol3 $\alpha$-glucuronide (P3G).

\section{Analysis of specimens \\ Microbiological tests}

Chlamydia samples were tested using a standardised commercial polymerase chain reaction (PCR) test (Cobas Amplicor, Roche Diagnostics), and HPV DNA samples using a generic GP5+/GP6+ primer mediated PCR system ${ }^{12}$ at the virology laboratory, Manchester Royal Infirmary. A Gap-DH PCR was performed to check the integrity of the DNA and for presence of PCR inhibitors. ${ }^{13}$ Type specific PCR detected HPV 6/11, 16, 18, 31, 33, 52, and 58. HSV-1 and HSV-2 antibodies were detected using an IgG ELISA (Gull Laboratories, Inc, USA). Cell cultures were used to detect HSV and if positive, typed by fluorescent staining using commercial monoclonal reagents. Gram stains for BV were read by one laboratory technician, following Nugent's criteria. A score of $>6$ defined presence of BV. Amsel criteria were used to classify seven slides that could not be graded. Other tests were completed at on-site laboratories. $N$ gonorrhoeae was cultured on lysed blood Columbia agar. Treponemal antibodies were measured (IgG/IgM Murex ICE syphilis assay). Microscopy for $T$ vaginalis and $C$ albicans was undertaken and yeasts were cultured on Sabouraud or blood agar plates.

\section{Hormonal tests}

A time resolved fluorescence immunoassay for the measurement of E3G and P3G in urine was used which had low interassay and intra-assay variation $(<6 \%) .{ }^{14}$ All urinary hormone measurements were creatinine standardised. ${ }^{15}$

\section{Data analysis \\ Menstrual patterns}

Definitions of the menstrual cycle were (i) "normal ovulatory," if between 21 and 41 days in length, the monitor registered an ovulatory event, the mid-luteal phase mean 3PG concentrations were above $2 \mu \mathrm{g} / \mathrm{ml}$ over three measurements, the follicular phase was less than 21 days and luteal phase at least 10 days in length, (ii) "disturbed ovulatory," if the follicular phase was 21 days or more and the luteal phase less than 10 days, (iii) "anovulatory," if the monitor registered no ovulatory event and/or P3G concentrations remained below $2 \mu \mathrm{g} / \mathrm{ml}$ following a luteinising hormone peak, (iv) oligomenorrhoea, if occurring at intervals of 42-180 days. To calculate gynaecological age adolescents were asked their year of menarche and if it was within the past year, between 1 and 2 years ago, 2 and 3 years ago, etc. The mid-point of the onset year of menarche was subtracted from the recruitment calendar age.

\section{Risk analysis and end points}

Frequencies of sexual behaviour and sociodemographic risk factors and biological markers were generated. Condom use at last sex was selected as a surrogate marker for general use. Univariate logistic regressions were performed for three infection end points: chlamydia, HPV DNA, BV. Odds ratios
Table 1 Sexual, biological, and hormonal characteristics of 127 female adolescents

\begin{tabular}{|c|c|c|}
\hline Characteristic present & $\%$ & (No) \\
\hline \multicolumn{3}{|l|}{ Sexual: } \\
\hline New partner in past 3 months & 29.1 & (34) \\
\hline$\geqslant 4$ lifetime partners & 64.3 & (81) \\
\hline Sexually active for $<1$ year & 30.7 & (39) \\
\hline $\begin{array}{l}\text { Usually has sexual intercourse } \\
\text { more than once per week }\end{array}$ & 76.3 & (97) \\
\hline Used condom at last sexual intercourse & 33.9 & (43) \\
\hline $\begin{array}{l}\text { Intercourse with new partner after } \\
\text { using drugs or alcohol (ever) }\end{array}$ & 56.7 & (72) \\
\hline Casual sex (ever) & 74.8 & (95) \\
\hline $\begin{array}{l}\text { Intercourse during menses during } \\
\text { past } 6 \text { months }\end{array}$ & 31.5 & (40) \\
\hline \multicolumn{3}{|l|}{ Was previously treated for: } \\
\hline Chlamydia & 19.3 & (22) \\
\hline Bacterial vaginosis & 8.8 & (10) \\
\hline Genital warts & 7.9 & (9) \\
\hline Previously pregnant & 11.8 & (15) \\
\hline Washes inside vagina after intercourse & 36.2 & (46) \\
\hline \multicolumn{2}{|l|}{ Biological: } & (93) \\
\hline Age of menarche $\leqslant 11.9$ years & 23.3 & (27) \\
\hline$<3.5$ years since menarche & 18.1 & (23) \\
\hline Short menstrual period ( $\leqslant 20$ days) & 12.7 & (15) \\
\hline Oligomenorrhoea (menses $42-180$ days) & 5.9 & (7) \\
\hline Body mass index $>25$ & 20.6 & (26) \\
\hline Tanner breast stage $5^{*}$ (self assessed) & 42.2 & (53) \\
\hline Tanner pubic hair stage 5 (self assessed) & 48.4 & (53) \\
\hline Ectopy present & 45.2 & (57) \\
\hline \multicolumn{3}{|l|}{ Hormonal contraception: } \\
\hline Current oral contraception & 46.5 & (59) \\
\hline Current progesterone contraceptiont & 12.6 & (16) \\
\hline Emergency contraception in last 12 months & 51.2 & (65) \\
\hline
\end{tabular}

Number with characteristic varies because of missing data). *Tanner stage 5 denotes full maturity. †Depo-provera, except for one subject with an implant.

(OR), 95\% confidence intervals (CI), and $\mathrm{p}$ values were calculated for each risk factor and each infection end point. ${ }^{16}$ In tables, reference categories for categorical variables are indicated; for dichotomous variables the OR is for the presence of the factor, and for continuous variables, it is for a unit increase in the observed value.

Chlamydia, HPV, and BV were analysed together in a multivariate analysis to test for differences in the risks for each infection, and to compute a pooled risk estimate. A binomial mixed effect model was used with subject fitted as a random effect. The $95 \%$ CIs were calculated for a single pooled OR for each factor. To test for heterogeneity in the response between the three infections, the infection by factor interaction was tested using a likelihood ratio test. These analyses used the xtlogit procedures in Stata (StataCorp, TX, USA).

Hormonal concentrations were transformed to a log scale. Median concentrations were determined before and after ovulation, and over the entire measured portion of the cycle. Correlations between biological risk factors, BV, HPV DNA and chlamydia, and median E3G and P3G concentrations were investigated, using Spearman's test for continuous variables and Mann-Whitney $U$ tests for dichotomous variables.

\section{RESULTS \\ Description of the population}

Between September 2000 and December 2001, 310 adolescents were approached to join the study; 124 were ineligible and 59 refused, providing a sample of 127. Mean age was 17.8 years (SD 1.1); $73 \%$ (92) were white, $24.6 \%$ (31) were black, or mixed race, and $2.4 \%$ (3) were Asian. Most were students $(51.5 \%, \mathrm{n}=65)$ and, of the remainder, $24.6 \%$ (31) 
Table 2 Prevalence of genital tract infections among adolescents attending genitourinary medicine clinics

\begin{tabular}{lcl}
\hline Infection & \% (No) & $95 \% \mathrm{Cl}$ \\
\hline HSV-2 (antibodies) & $4.3(116)$ & 1.4 to 9.8 \\
HSV-1/HSV-2 (viral shedding) & $3.9(127)^{*}$ & 1.3 to 8.9 \\
HPV DNA & $64.4(90) \dagger$ & 53.7 to 74.3 \\
Ano-genital warts & $16.9(89)$ & 9.8 to 26.3 \\
Chlamydia & $26.8(127)$ & 19.3 to 35.4 \\
Gonorrhoea & $1.6(127)$ & 0.2 to 5.6 \\
Candidiasis & $6.3(127)$ & 0.3 to 12.0 \\
Bacterial vaginosis & $33.9(127)$ & 25.7 to 42.8 \\
Trichomoniasis & $3.1(127)$ & 0.9 to 7.9 \\
Syphilis & $0.0(127)$ & 0.0 to 2.9 \\
No infection & $15.6(90)$ & 8.8 to 24.7 \\
Single infection & $43.3(90)$ & 32.9 to 54.2 \\
Two or more infections & $44.1(90)$ & 34.0 to 55.3 \\
\hline *Includes two girls who did not give swabs because of painful herpes lesions. \\
tHPV screening started after 3 months.
\end{tabular}

were working and 23.8\% (30) were unemployed. Parental occupations were unskilled/unemployed $(40 \%, \mathrm{n}=48)$, professional $(38.3 \%, n=46)$, or skilled $(21.7 \%, n=26)$. Many adolescents smoked $(58.3 \%, \mathrm{n}=74)$ or used to smoke $(25.2 \%$, $\mathrm{n}=32$ ). Other characteristics are summarised in table 1 . All were sexually active; $18.1 \%$ were of young gynaecological age $(<3.5$ years $)$, and almost half described themselves as not fully developed (less than Tanner stage 5 for breast and pubic hair).

\section{Prevalence of genital tract infections}

The three most common adolescent infections were HPV DNA (64.4\%), BV (33.9\%), and chlamydia (26.8\%) (table 2 ). Of the $58 \mathrm{HPV}$ DNA positive samples, $55.2 \%$ (32) could be typed, showing 28 high risk types (16, 18, 31, 33), five low risk types (6/11), and one dual high and low risk type. Multiple genital infections were common; $56.9 \%$ (33) of adolescents with HPV DNA had at least one co-infection.
Risk factors associated with chlamydia, HPV, and BV Risk factors significantly associated with lower risk of all three infections were breast maturity, gynaecological age, long menstrual cycles (oligomenorrhoea), and professional parental occupation (table 3). A new partner after drinking or drug use significantly increased the risk of all infections, as did vaginal cleansing. Gynaecological age (but not breast stage, ectopy, or long cycles) remained a significant predictor of the three infections ( $\mathrm{OR}=0.7,0.6$ to $09 ; \mathrm{p}=0.008$ ) after controlling for age, number of sex partners and eight other behavioural risk factors ( $\mathrm{cf}$ table 3 ).

Several behavioural factors showed significant differences between infections. Smoking was a positive risk factor for chlamydia and BV, but a negative risk factor for HPV $(p=0.007)$. A recent new partner was associated with a higher risk of HPV and BV, but a lower risk of chlamydia $(p=0.024)$. Sex during a menstrual period was associated with a higher risk of $\mathrm{BV}(\mathrm{p}=0.003)$, but not chlamydia or

Table 3 Individual and pooled risk factors for chlamydia, HPV and bacterial vaginosis

\begin{tabular}{|c|c|c|c|c|c|c|}
\hline \multirow[b]{2}{*}{ Risk factor } & \multirow{2}{*}{$\begin{array}{l}\text { Chlamydia } \\
\text { OR }(95 \% \mathrm{Cl}) \dagger\end{array}$} & \multirow{2}{*}{$\begin{array}{l}\text { HPV } \\
\text { OR }(95 \% \mathrm{Cl}) \dagger\end{array}$} & \multirow{2}{*}{$\frac{\text { BV }}{\text { OR }(95 \% \mathrm{Cl}) \dagger}$} & \multicolumn{2}{|c|}{$\begin{array}{l}\text { Pooled estimate (three } \\
\text { infections) }\end{array}$} & \multirow{2}{*}{$\begin{array}{l}\text { Heterogeneity* } \\
\text { p Value }\end{array}$} \\
\hline & & & & OR $(95 \% \mathrm{Cl})+\dagger$ & p Value & \\
\hline \multicolumn{7}{|l|}{ Parental occupation } \\
\hline Professional & Reference & & & & & \\
\hline Semiskilled & $3.6(1.0$ to 12.8$)$ & $0.8(0.2$ to 2.5$)$ & $1.9(0.7$ to 5.2$)$ & $1.7(0.8$ to 3.5$)$ & & \\
\hline Unskilled/unemployed & $4.9(1.6$ to 14.8$)$ & $1.4(0.5$ to 3.7$)$ & $1.5(0.6$ to 3.7$)$ & $2.1(1.2$ to 4.0$)$ & 0.043 & 0.20 \\
\hline Ever smoked & $1.2(0.4$ to 3.6$)$ & $0.1(0.0$ to 0.9$)$ & $2.5(0.8$ to 8.0$)$ & $1.0(0.5$ to 2.0$)$ & 0.97 & 0.006 \\
\hline Frequency of $\operatorname{sex}^{* *}-$ & $1.0(0.6$ to 1.7$)$ & $1.3(0.7$ to 2.4$)$ & $2.0(1.1$ to 3.4$)$ & $1.4(1.0$ to 2.0$)$ & 0.065 & 0.18 \\
\hline New partner after drugs/alcohol & $1.9(0.8$ to 4.3$)$ & $3.4(1.4$ to 8.5$)$ & $1.3(0.6$ to 2.7$)$ & $2.0(1.2$ to 3.4$)$ & 0.009 & 0.20 \\
\hline New partner in last 3 months & $0.3(0.1$ to 0.9$)$ & $2.2(0.8$ to 6.4$)$ & $1.3(0.6$ to 2.9$)$ & $1.0(0.6$ to 1.8$)$ & 0.98 & 0.013 \\
\hline Practised sex during period & $0.9(0.4$ to 2.1$)$ & $0.6(0.2$ to 1.5$)$ & 3.3 (1.5 to 7.2$)$ & $1.3(0.8$ to 2.3$)$ & 0.30 & 0.008 \\
\hline Cleansed vagina after sex & $2.2(0.9$ to 5.3$)$ & $2.2(0.7$ to 6.4$)$ & 2.5 (1.1 to 5.9$)$ & 2.3 (1.4 to 3.9$)$ & 0.002 & 0.96 \\
\hline Condom at last sex & $0.3(0.1$ to 0.9$)$ & $1.0(0.4$ to 2.3$)$ & $0.8(0.4$ to 1.7$)$ & $0.6(0.4$ to 1.1$)$ & 0.089 & 0.20 \\
\hline Gynaecological age** & $0.7(0.5$ to 0.9$)$ & $0.8(0.6$ to 1.0$)$ & $0.8(0.6$ to 1.0$)$ & $0.7(0.6$ to 0.9$)$ & 0.001 & 0.50 \\
\hline $\begin{array}{l}\text { Emergency contraception (last } \\
12 \text { months) }\end{array}$ & $2.5(1.1$ to 5.9$)$ & $0.7(0.3$ to 1.7$)$ & $0.9(0.4$ to 1.8$)$ & $1.2(0.7$ to 2.0$)$ & 0.54 & 0.054 \\
\hline Breast stage (Tanner) ${ }^{* *}$ & $0.6(0.3$ to 1.1$)$ & $0.6(0.3$ to 1.2$)$ & $0.6(0.4$ to 1.1$)$ & $0.6(0.4$ to 0.9$)$ & 0.082 & 0.98 \\
\hline \multirow{2}{*}{\multicolumn{7}{|c|}{ Cycle regularity (days) }} \\
\hline & & & & & & \\
\hline $21-42$ & Reference & & & & & \\
\hline$<20$ & $2.2(0.7$ to 7.0$)$ & $0.9(0.2$ to 3.6$)$ & $2.0(0.6$ to 6.2$)$ & $2.0(0.6$ to 6.2$)$ & & \\
\hline >42 (oligomenorrhoea) & NA & $0.3(0.1$ to 1.8$)$ & $0.3(0.0$ to 2.6$)$ & $0.3(0.0$ to 2.6$)$ & 0.027 & 0.21 \\
\hline "irregular" & 0.7 (0.2 to 2.3$)$ & $3.5(0.7$ to 17.8$)$ & $0.5(0.2$ to 1.6$)$ & $1.4(0.6$ to 3.0$)$ & & \\
\hline
\end{tabular}

†Univariate logistic regression.

t†Pooled estimate of the risk of infection assuming the risks of the three infections do not differ (multivariate logistic regression).

*Significance level of a test that the risks are not homogeneous across the three infections. Significance suggests that the three infections may have different responses to the risk factor.

**Entered as continuous variables. Gynaecological age is expressed as risk per year, frequency of sex is grouped into three categories: $\leqslant 1,1-4$, and $>4$ times per week.

-Variables entered into the adjusted analysis, together with calendar age and lifetime number of partners.

NA, not computable because of zero events. 
HPV. In univariate analyses, use of emergency contraception was associated with increased chlamydia risk $(\mathrm{p}=0.024)$ and using condoms at last sex with lower risk $(\mathrm{p}=0.015)$.

\section{Correlations with E3G and P3G hormonal concentrations}

Altogether, 49 adolescents not using hormonal contraceptives collected a home fertility monitor. Of these 19 failed to collect any data, two became pregnant, and three developed oligo-amenorrhoea. Of 25 adolescents completing the study, cycles of $10(40 \%)$ were normal, eight (32\%) disturbed ovulatory, and seven (28\%) anovulatory.

Correlations between median sex steroid hormone concentrations, and presence or absence of biological characteristics and genital tract infections were assessed. Adolescents who were chlamydia positive were more likely to have elevated P3G concentrations (Mann-Whitney U test: $p=$ 0.05). BMI was inversely correlated with P3G concentrations (Spearman: $r=-0.40 ; \mathrm{p}=0.05$ ). There were no significant correlations of the biological factors listed in table 3, or genital infections (chlamydia, HPV DNA, BV) with median E3G concentrations.

\section{DISCUSSION}

In this study of adolescents attending genitourinary medicine clinics, younger gynaecological age was associated with a high risk of genital infections. Adolescents with oligomenorrhoea, a menstrual disorder associated with ovulatory dysfunction, ${ }^{17}$ had a lower overall risk.

This study was unique because it investigated biological risk markers, whereas most research has focused on sexual risk behaviour and young age. ${ }^{18}$ One exception was a study in racially diverse adolescents, which reported a significant fall in vaginal $\mathrm{pH}$ as gynaecological age increased. ${ }^{19}$ Vaginal $\mathrm{pH}$ could account for increased risk of $\mathrm{BV}$ in less mature adolescents. Biological susceptibility was inferred by previous studies that could not account for a disproportionate risk of sexually transmitted infections among female adolescents,,$^{20}$ and in studies finding high infection rates among adolescents with a history of few sexual partners. ${ }^{3}$ In our study, the high infection rate was not explained by recent onset of sexual activity, ${ }^{21}$ although the timing of onset is critical. We suggest that a sexually active 18 year old with late menarche may be more susceptible to multiple infections than a sexually active 15 year old with early menarche.

We also assessed menstrual cycle patterns and hormonal concentrations in a subgroup of 25 adolescents not using contraception. Among these, $60 \%$ had disturbed menstrual cycles. The sample size was insufficient for subgroup analysis of menstrual patterns and infection rates, reflecting the difficulties of following up a high risk population who frequently used contraceptives. Contraceptives help to normalise menstrual cycle patterns, and in the total sample, contraceptive use (except emergency contraception) did not significantly increase the risk for any infection end point. Analysis of hormone concentrations identified an association between higher P3G and chlamydia. This was of interest because in the total sample, adolescents who had used emergency contraception, containing levonorgestrel, in the past 12 months, had a 2.5 times increased risk of chlamydia. This could be the result of unprotected sex as condom use was protective (table 3). However, none of seven adolescents with oligomenorrhoea, a menstrual disorder associated with lower progesterone levels, was chlamydia positive (table 3 ). $C$ trachomatis preferentially infects endocervical columnar cells present on the ectocervix, and these cells bind progesterone
Key messages

- Young gynaecological age increased susceptibility of adolescents to chlamydia, human papillomavirus, and bacterial vaginosis

- Gynaecological age is a useful marker of adolescent risk

- Adolescents using emergency contraception were twice as likely as non-users to have chlamydia

at high levels..2 ${ }^{22}$ These results suggest that higher progesterone levels increase chlamydia risk.

Self assessment of maturity stages may have been less accurate than clinical assessment and the selection criteria excluded older adolescents with early menarche. Early maturers $(<12$ years $)$ have elevated oestrogen levels, a faster rate of pubertal progression than late maturers, ${ }^{4}$ achieve regular menstrual patterns sooner, tend to be heavier, ${ }^{23}$ and have lower pregnanediol levels. ${ }^{24}$ This profile could contribute to reduced biological susceptibility to genital infections for a given exposure rate. Black girls experience menarche earlier than white girls ${ }^{25}$ and future studies should be large enough to stratify by gynaecological age and ethnicity.

Whereas young gynaecological age increased susceptibility to all three infections, behavioural risk factors were often infection specific. Other associations may have been detected had we elicited histories of different types of sexual practice (for example, anal sex) or verified sexual histories. The lower risk of chlamydia in adolescents with a new recent partner might be explained by a lower prevalence of chlamydia in adolescent male partners or by higher condom use with new partners. Condoms may be more protective against chlamydia than HPV, which can appear at sites not covered by the condom. ${ }^{26}$ Smoking, a marker for high risk behaviour, is also anti-oestrogenic. ${ }^{27}$ Smoking protected against HPV infection in this and a previous US cohort study. ${ }^{28}$ Future studies might explore whether perceptions of size (for example, breast development and weight) influence partner selection, sexual behaviour, and infection risk.

\section{Implications}

Adolescents exposed to genital infections at younger gynaecological ages are highly susceptible. Exposure to multiple infections is a consequence of risky sexual behaviour and was characteristic of these adolescents. Co-infections with HPV were frequent. Elevated levels of the cytokine IL-12 have been detected in adolescents concomitantly infected with both HPV and one or more STIs. ${ }^{29}$ Presence of HPV may influence the magnitude of immune protection in the genital tract. Associations between multiple infections, gynaecological age, and long term sequelae need to be investigated in longitudinal studies. Age at first sexual intercourse has declined, which potentially increases the proportion of adolescents exposed before maturity. Gynaecological age is a useful marker of adolescent risk and we recommend its inclusion in clinical assessment.

\section{ACKNOWLEDGEMENTS}

This study was funded by a grant from the Max Elstein Trust, which included a research fellowship for Eleanor Fairbrother. We wish to thank the staff and patients at the three genitourinary medicine clinics for their cooperation and support for the study, Andrew Bailey for microbiological tests, Christine Glenn for help with urinary hormone assays, and Professor Bernard Brabin for editing the manuscript. Unipath Limited kindly donated and programmed the fertility monitors used in the study. 


\section{CONTRIBUTORS}

LB conceived the study and wrote the paper; EB contributed to study design, recruited participants, and helped draft the paper; DM, SPH and SC advised on clinical issues, collected the data, and reviewed the paper; SR undertook the statistical analyses and contributed to writing the paper; PW and GB completed the hormone assays, advised on hormonal analyses, and reviewed the paper; HCK reviewed the study design and analysis.

\section{Authors' affiliations}

L Brabin, E Fairbrother, H C Kitchener, Academic Unit of Obstetrics and Gynaecology and Reproductive Health Care, University of Manchester, UK

D Mandal, Manchester Centre for Sexual Health, Manchester Royal Infirmary, UK

S A Roberts, Biostatistics Group, School of Epidemiology and Health Sciences, University of Manchester, UK

S P Higgins, Department of Genitourinary Medicine, North Manchester General Hospital, UK

S Chandiok, Sexual Health Clinic, Withington Hospital, Manchester, UK P Wood, Regional Endocrine Unit, University of Southampton, UK G Barnard, Centre for Veterinary Science, Department of Clinical Veterinary Medicine, University of Cambridge, UK

\section{REFERENCES}

1 PHLS Communicable Diseases Surveillance Centre. Sexual health in Britain. London, 2002 July.

2 Johnson AM, Mercer CH, Erens B, et al. Sexual behaviour in Britain: partnerships, practices and HIV risk behaviours. Lancet 2001;358:1135-42.

3 Bunnell RE, Dahlberg L, Rolfs R, et al. High prevalence and incidence of sexually transmitted diseases in urban adolescent females despite moderate risk behaviors. J Infect Dis 1999;180:1624-31.

4 Apter D. Development of the hypothalamic-pituitary-ovarian axis. Ann N Y Acad Sci 1997;816:9-21

5 Moscicki A-B, Ma Y, Holland C, et al. Cervical ectopy in adolescent girls with and without human immunodeficiency virus. J Infect Dis 2001;183:865-70.

6 Kutteh WH, Moldoveanu Z, Mestecky J. Mucosal immunity in the female reproductive tract: correlation of immunoglobulins, cytokines and reproductive hormones in human cervical mucus around the time of ovulation. AIDS Res Hum Retroviruses 1998;14:S51-5.

7 Baeten JM, Nyange PM, Richardson BA, et al. Hormonal contraception and risk of STD acquisition: results from a prospective study. Am J Obstet Gynecol $2001 ; 185: 380-5$

8 Brabin L. Hormonal markers of susceptibility to sexually transmitted infections: are we taking them seriously? BMJ 2001;323:394-5.

9 Duke PM, Litt IF, Gross RT. Adolescent self assessment of sexual maturation. Pediatrics 1980;66:918-20.

10 Wilcox MH, Reynolds MT, Hoy CM, et al. Combined cervical swab and urine specimens for PCR diagnosis of Chlamydia trachomatis infection. Sex Transm Infect 2000;76:177-78.

11 Behre HM, Kuhlage J, Gaßner C, et al. Prediction of ovulation by urinary hormone measurements with the home use ClearPlan fertility monitor: comparison with transvaginal ultrasound scans and serum hormone measurements. Hum Reprod 2000;15:2478-82.

12 De Roda Hunsman AM, Walboomers JMM, Van den Brule AJC, et al. The use of general primers GP5 and GP6 elongated at their 3' ends with adjacent highly conserved sequences improves human papillomavirus detection by PCR. J Gen Virol 1995;76:1057-62.

13 Mclaughlan JM, Seth R, Vautier G, et al. Interleukin-8 and inducible nitric oxide synthase mRNA levels in inflammatory bowel disease at first presentation. J Pathol 1997;181:87-92.

14 Kesner JS, Knecht EA, Krieg EF, et al. Validations of time-resolved fluoroimmunoassays for urinary estrone 3-glucuronide and pregnanediol 3glucuronide. Steroids 1994;59:205-11.

15 Munro CJ, Stabenfeldt GT, Cragun JR, et al. Relationship of serum estradiol and progesterone concentrations to the excretion profiles of their major urinary metabolites as measured by enzyme immunoassay and radioimmunoassay. Clin Chem 1991;7:838-44.

16 Ihaka R, Gentleman R. A language for data analysis and graphics. J Comp Graph Stats 1996:5:299-314.

17 Van Hooff MHA, Voorhorst FJ, Kaptein MBH, et al. Predictive value of menstrual cycle pattern, body mass index, hormone levels and polycystic ovaries at age 15 years for oligo-amenorrhoea at age 18 years. Hum Reprod 2004:19:383-92.

18 Creighton S, Edwards S, Welch J, et al. News from the frontline: sexually transmitted infections in teenagers attending a genitourinary clinic in south east London. Sex Transm Infect 2002;78:349-51

19 Steven-Simons C, Jamison J, McGregor JA, et al. Racial variation in vaginal $\mathrm{pH}$ among healthy sexually active adolescents. Sex Transm Dis 1994;21:168-72

20 Buvé $\mathbf{A}$, Weiss HA, Laga $M$, et al. The epidemiology of gonorrhoea, chlamydia infection and syphilis in four African cities. AIDS 2001;15(Suppl 4):S79-88

21 Collins S, Mazloomzadeh S, Winter $\mathrm{H}$, et al. High incidence of cervical human papillomavirus infection in women during their first sexual relationship. Br J Obstet Gynaecol 2002;109:96-8.

22 Jacobson DL, Peralta L, Graham NMH, et al. Histologic development of cervical ectopy. Relationship to reproductive hormones. Sex Transm Dis 2000;27:252-58

23 Tanner JM. Growth at adolescence, 2nd ed. Oxford: Blackwell Scientific Publications, 1962.

24 Windham GC, Elkin E, Fenster L, et al. Ovarian hormones in premenopausal women: variation by demographic, reproductive and menstrual cycle characteristics. Epidemiology 2002;13:675-84.

25 Freedman DS, Khan LK, Serdula MK, et al. Relation of age at menarche to race, time period, and anthropometric dimensions. The Bogalusa Heart Study. Pediatrics 2002:1 10 (www.pediatrics.org/cgi/content/fall/1 10/4/e43).

26 Manhart LE, Koutsky LA. Do condoms prevent genital HPV infection, external genital warts or cervical neoplasia? A meta-analysis. Sex Transm Dis 2002;29:725-35.

27 Tankó LB, Christiansen C. An update on the antiestrogenic effect of smoking: a literature review with implications for researchers and practitioners. Menopause 2003; 11:104-9.

28 Moscicki A-B, Shiboski S, Broering J, et al. The natural history of human papillomavirus infection as measured by repeated DNA testing in adolescent and young women. J Pediatr 1998;132:277-84

29 Crowley-Nowick PA, Ellenberg JH, Vermund SH, et al. Cytokine profile in genital tract secretions from female adolescents: impact of human immunodeficiency virus, human papillomavirus, and other sexually transmitted pathogens. J Infect Dis 2000;181:939-45. 